\title{
An Economic Model for Geothermal Energy Consumption Based on Industrial Innovation and Structural Upgrading
}

\author{
Le Ma \\ Department of National Defense Economy, Army Logistics University of PLA, Chongqing 401331, China
}

Corresponding Author Email: 1032450349@qq.com

https://doi.org/10.18280/ijht.370315

Received: 10 March 2019

Accepted: 27 June 2019

\section{Keywords: \\ geothermal energy, economic model, industrial innovation, energy} consumption, optimization

\begin{abstract}
Geothermal energy is a clean and renewable energy. If developed and utilized efficiently, the geothermal energy would contribute greatly to the sustainable development of the energy industry. To improve the efficiency and economy of geothermal utilization, this paper examines the mechanism of the structural upgrading and industrial innovation of the energy structure, based on the existing methods of the energy industry. Next, an economic model was established for geothermal energy consumption, and optimized through mathematical analysis, in the light of the factors affecting the sustainable energy development. The research results show that: the mining and utilization of geothermal energy are influenced by climate, geology and mining method; our economic model for geothermal energy consumption considers the construction cost under multiple energy utilization scenarios; the optimized economic model for geothermal energy consumption can enhance the energy efficiency, and promote the economic and social benefits of geothermal energy industry. This research lays the theoretical basis for sustainable development energy, the coordinated development between energy and environment, and the mining and utilization of geothermal energy and other clean and renewable energies.
\end{abstract}

\section{INTRODUCTION}

The rational use of energy is the main impetus to social and economic development. If energy is not utilized or developed sustainably, it would be impossible to coordinate the development of energy, economy, society, environment and ecology [1-3]. However, the booming global economy, coupled with the rising living standards, has increased the energy demand year by year, making it difficult to be fulfilled by the current reserves of oil, coal and natural gas [4-5]. The main problem with energy development lies in the contradiction between the lack of energy resources and the growing energy demand for social progress. To solve the problem, it is necessary to develop new renewable and green energy sources that help mitigate the conflicts between society, economy and environment, paving the path towards an ecofriendly society [6-8].

Geothermal resources refer to the thermal energy and other useful components in exploitable rocks. The earth's crust contains a huge amount of geothermal resources, which are immune to environmental and seasonal changes. If developed rationally, such resources can be used to generate power for living and production needs, and support heating or cooling in buildings [9-10]. For example, geothermal heating can reduce the transport and consumption of coal, oil and natural gas, cut down the emissions of harmful substances, and thus suppress environmental pollution [11-13]. Recent years has seen a rapid growth in the development of geothermal energy, thanks to the advancement of geothermal mining technology and the growing awareness of new energy development. But the current development mode is yet to be improved in terms of energy-efficiency and greenness [14-15]. The heating systems and consumption modes of geothermal energy should undergo technical innovation and structural upgrading to satisfy the demand for ecological and economic development, and to produce better economic benefits.

In the light of the above, this paper optimizes the mining and utilization modes of geothermal resources based on industrial innovation and structural upgrading, aiming to achieve sustainable exploitation and use of green resources and promote social and economic development. Specifically, an economic model was established to describe geothermal energy consumption, and optimized with the latest theories and methods of technical optimization. The research findings provide the theoretical basis for efficient mining and use of geothermal resources, sustainable development of energy and the coordination between society, economy and environment.

\section{INDUSTRIAL INNOVATION AND STRUCTURAL UPGRADING IN ENERGY CONSUMPTION AND ECONOMIC DEVELOPMENT}

\subsection{Structural upgrading of energy industry}

The industry of a country or a region usually consists of multiple layers, namely, industrial structure, industrial division, type of industry, product, region and technology. Among them, the industrial structure stands out for its impacts on the overall trend of regional industry [16-18]. For energy industry, the industrial structure is made up of various sectors. The combination and correlation of different sectors directly bear on how the energy industry affects social and economic development. 
The upgrading of industrial structure is to continuously transform and adjust the sectoral pattern of an industry, such that the irrational structure evolves towards a high-level and rational direction. The structural upgrading of industries is the key to the steady progress of society and economy. For the development and utilization of energy (e.g. geothermal energy), the structural upgrading of the energy industry is the crux for the sustainable development of environment and resources, and the coordinated development of society, economy and ecology.

Currently, the energy-intensive industry is gradually declining because the available energy is severely limited and supplied first to other higher-priority industries. Against this backdrop, the structural upgrading of the energy industry requires interventions in the following three aspects:

structure, system and technology. The structural upgrading of the energy industry under energy constraint is shown in Figure 1 below.

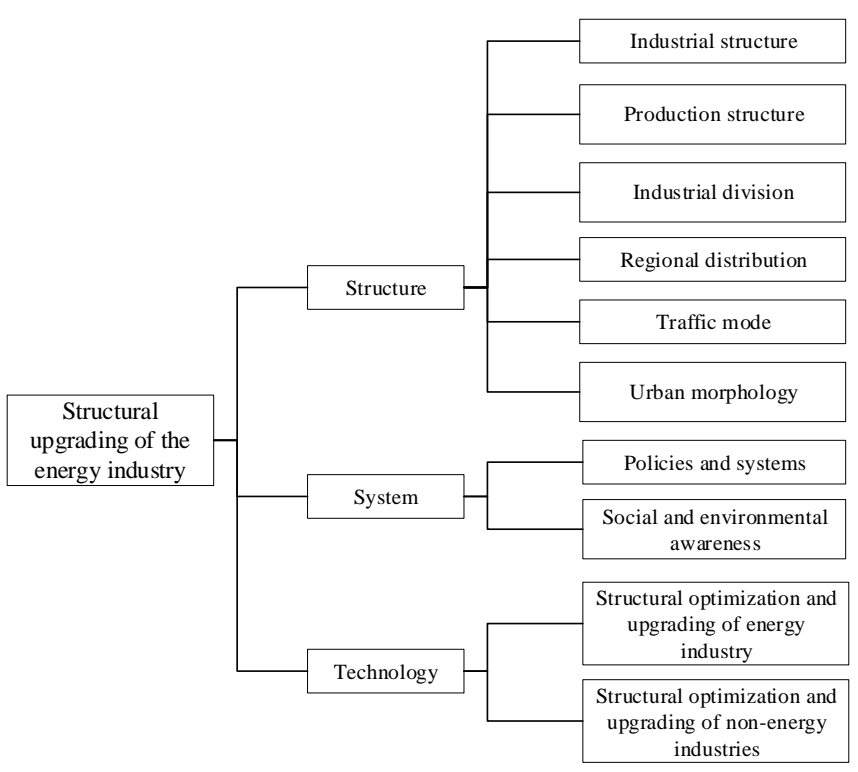

Figure 1. Structural upgrading of the energy industry under energy constraint

\subsection{Industrial innovation of energy industry}

In addition to structural upgrading, the sustainable development of the energy industry also relies on the reform of the energy utilization mode. To improve energy efficiency and allocation, the reform should integrate innovative yet practical technologies with advanced knowledge, system, and management philosophy [19-21].

To achieve the above objectives, it is a must to implement industrial innovation of the energy industry. Firstly, the technology should be innovated and improved to a high level. Secondly, the management should be innovated to sort out the relations between technology, talent, knowledge and system. Thirdly, the innovation should focus on the development of independent intellectual property rights. Fourthly, efforts should be paid to develop clean energies like solar energy, wind energy, tidal energy and geothermal energy, such as to reduce the reliance of social progress on nonrenewable energies (e.g. oil and coal).

As shown in Figure 2, the innovation of the energy industry requires policy support, technology development and the adjustment of the energy structure. From these three perspectives, the reform and innovation of the energy industry will promote the social and economic development, and enhance the sustainability of the energy environment in China.

Being an emerging clean energy, the geothermal energy should be subjected to industrial innovation and structural upgrading, in order to improve the efficiency of mining and utilization of geothermal resources. In the following sections, geothermal heating is cited as an example to evaluate the economy of geothermal energy consumption.

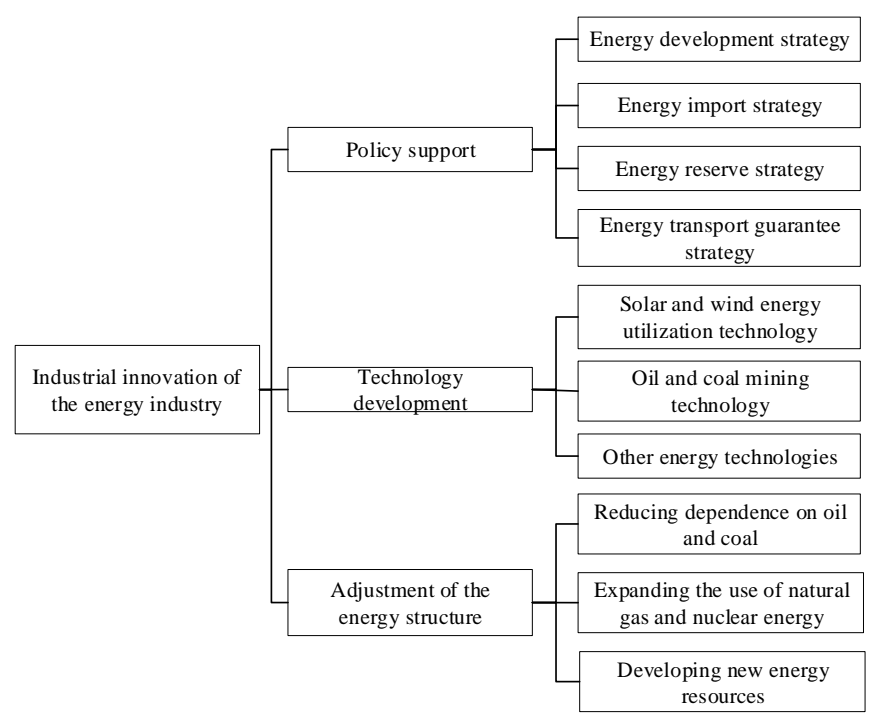

Figure 2. Industrial innovation of the energy industry

\section{CONSTRUCTION AND OPTIMIZATION OF ECONOMIC MODEL OF GEOTHERMAL ENERGY CONSUMPTION}

\subsection{Construction of economic model of geothermal energy consumption}

In recent years, geothermal heating has gradually entered our lives. To evaluate the economy of a geothermal heating system, an economic model should be established based on multiple influencing factors. The common geothermal heating systems can be divided into direct heating systems and indirect heating systems. For direct heating, the geothermal heat is utilized rather inefficiently, owing to the corrosive nature of geothermal water and the material properties of the pipe network. What is worse, the water flow of the geothermal heating system is not easily adjustable. Therefore, direct heating has a limited scope of application. By contrast, indirect heating is suitable for largescale centralized heat supply. The indirect heating systems can realize stable heat supply, as the thermal energy is transmitted via exchange station and carried by circulating water.

For an indirect heating system, the geothermal water flow increases exponentially with the decline in outdoor temperature, when the temperature of the circulating water remains unchanged (Figure 3 ). The relative efficiency of this heating system exhibits a declining trend, if the outdoor temperature is below the designed level (Figure 4). In this case, the building loses much of its heat, reducing the temperature of the return water in the geothermal heating system. The water supply temperature will also drop, which in turn lowers the indoor temperature. Hence, the indoor heat dissipation system will perform less efficiently. 


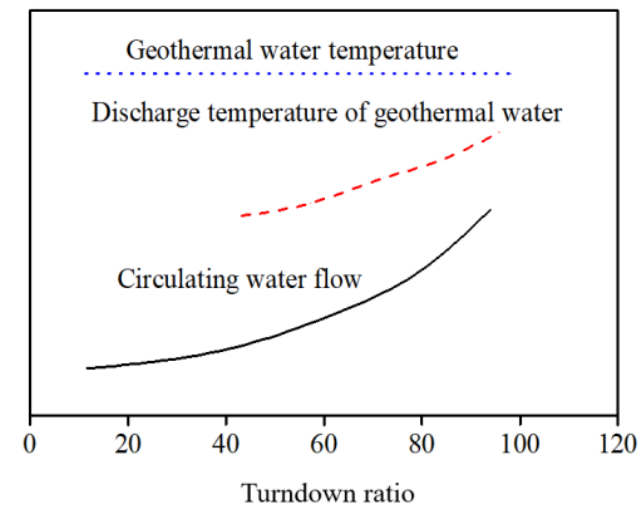

Figure 3. Water volume control of indirect geothermal heating system

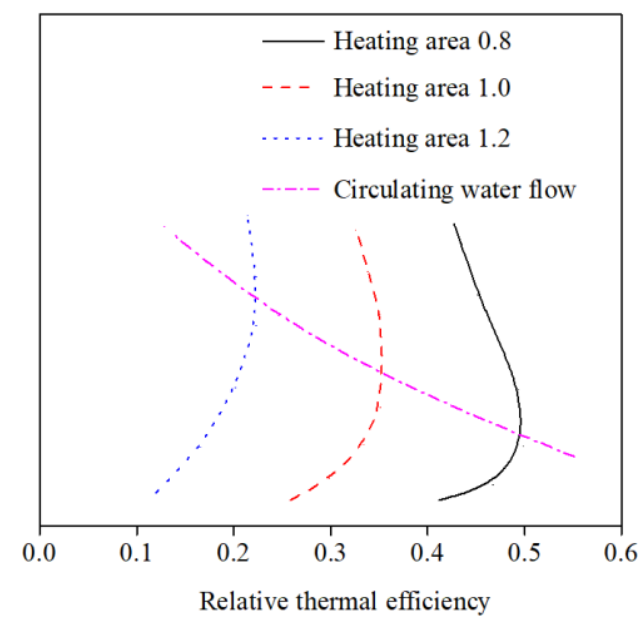

Figure 4. Variation of relative thermal efficiency $\eta$ with circulating water flows

To give full play to the energy-efficiency and greenness of geothermal energy, a geothermal heating system should have as many geothermal wells as possible (without exceeding the maximum load of the system) to mine geothermal energy. However, the geothermal wells are very costly to build. As a result, all influencing factors of geothermal energy development and utilization should be identified, and used to develop a suitable economic model for the geothermal heating system. Then, the economy of the system can be evaluated and controlled with the model.

Considering the short presence of maximum heat load, the geothermal heating system should combine the basic load with the variable load. The peak shaving should be adopted to improve the efficiency and reduce the cost of geothermal energy utilization, without sacrificing the greenness, energy conservation and operation stability. In general, the peak shaving of the geothermal heating system is implemented by adjusting the peak-shaving ratio, i.e. the percentage of the variable load to the total heating load of the system. The designed peak-shaving ratio $\mu$ and the heating area after peak shaving $A_{f}$ can be respectively computed by:

$$
\begin{gathered}
\mu=\frac{q_{f}}{q_{s}} \times 100 \% \\
A_{f}=\frac{A_{d}}{(1-\mu)} \times 100 \%
\end{gathered}
$$

where, $q_{f}$ and $q_{s}$ are the variable load and the designed heat load per unit area, respectively $\left(\mathrm{kW} / \mathrm{m}^{2}\right) ; A_{d}$ is the heating area before peak shaving $\left(\mathrm{m}^{2}\right)$. The amount of heat $Q_{r}$ released by geothermal water can be expressed as:

$$
Q_{r}=\frac{c \times\left(t_{r}-t_{p}\right) g_{r}}{3.6}
$$

where, $\mathrm{c}$ is the specific heat capacity of water $\left(\mathrm{kJ} / \mathrm{kg} \cdot{ }^{\circ} \mathrm{C}\right) ; t_{r}, t_{p}$ and $g_{r}$ are the production temperature $\left({ }^{\circ} \mathrm{C}\right)$, discharge temperature $\left({ }^{\circ} \mathrm{C}\right)$ and flow of geothermal water, respectively.

In a real-world scenario, the heat supply to a building changes cyclically in the heating cycle, and exhibits cyclic changes with temperature in each day. The heating parameters of an indirect geothermal heating system and the two constants $C_{3}$ and $C_{4}$ can be respectively obtained by:

$$
\begin{gathered}
C_{3} Q_{t d}+C_{4} Q_{t d}^{\frac{1}{1+\beta}}+T_{h}-T_{a}=0 \\
C_{3}=f\left(C_{q}, G_{c}, G_{h}, S, C_{p}\right), C_{4}=(A, \alpha)^{-\frac{1}{1+\beta}}
\end{gathered}
$$

where, $G_{\mathrm{h}}$ and $G_{\mathrm{c}}$ are the flows of geothermal water and circulating water, respectively $(\mathrm{kg} / \mathrm{s}) ; S_{r}$ and $S$ are the heat transfer areas of the ultimate heat sink and the exchange station, respectively $\left(\mathrm{m}^{2}\right) ; k$ is the total heat transfer coefficient of the exchange station $\left(\mathrm{W} /\left(\mathrm{m}^{2} \cdot{ }^{\circ} \mathrm{C}\right)\right) ; \alpha$ and $\beta$ are the heat dissipation coefficients of the ultimate heat sink; $F$ is the correction factor of the exchange station.

For an indirect geothermal heating system, the utilization efficiency of geothermal energy can be increased by controlling the flow of geothermal water. The maximum heat can be obtained under the following condition:

$$
\frac{m R_{2}^{m}}{\left(R_{2}^{m}+\frac{C_{1}}{C_{2}}\right)}=\frac{0.5 P+\varepsilon_{2}}{\varepsilon_{1}}
$$

where, $R_{2}=G_{h} / G_{c}\left(P_{h}\right.$ and $P_{c}$ are the temperature efficiencies of exchange station); $C_{1}$ and $C_{2}$ are empirical indices; $\varepsilon_{1}$ and $\varepsilon_{2}$ are efficiency coefficients (depending on the performance parameters of the heating system and the temperature efficiencies of the exchange station). In the exchange station, the discharge temperature, heat exchange amount and flow of the circulating water being heated by geothermal water obey the relationships in Figure 5.

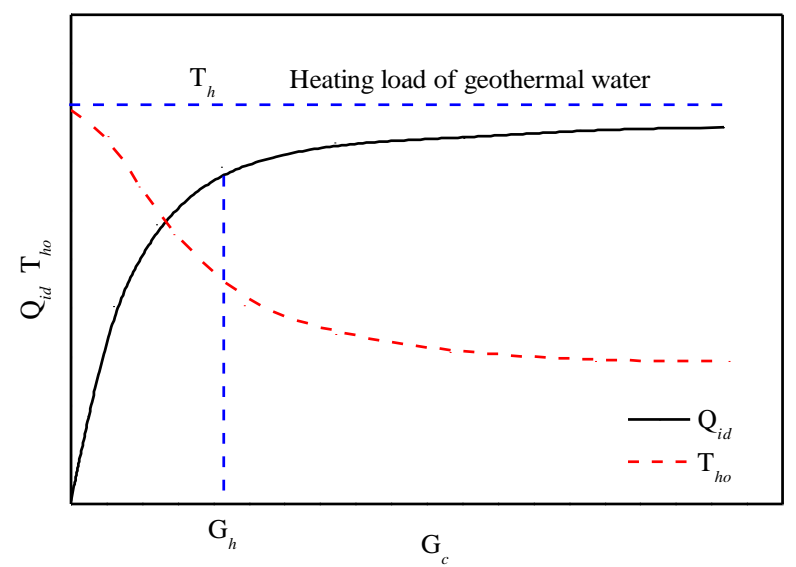

Figure 5. The relationships between the discharge temperature, heat exchange amount and flow of the circulating water being heated by geothermal water in the exchange station 
The optimization model of the geothermal heating system mainly computes the cumulative heat of the peak-shaving heat source by fitting the heating degree day (HDD) curve. In this paper, the HDD data of a region are collected, and fitted by the least squares (LS) method, outputting a fourth-order polynomial equation about the HDD and temperature:

$$
\begin{gathered}
\mathrm{y}=0.0007 x^{4}-0.189 x^{3}+0.0102 x^{2} \\
+10.1206 x+71.628
\end{gathered}
$$

The mean square error (MSE) was thus computed as 2.84 . The fitting curve between the HDD and outdoor temperature is shown in Figure 6 below.

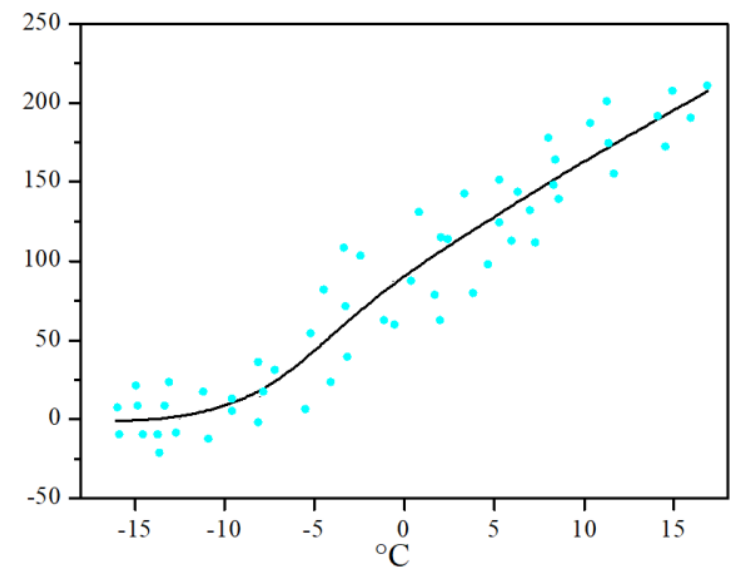

Figure 6. Fitting curve between the HDD and outdoor temperature

Based on the above analysis, this paper optimizes the economy of geothermal heating, i.e. improves the utilization efficiency of geothermal energy, by setting up a suitable mathematical model that minimizes the cost of geothermal heating system. Specifically, the annual worth method was adopted to calculate the construction cost per unit heating area and the annual operating cost per unit heating area. The total construction cost was distributed to each year and superimposed with the annual operating cost as the heating cost of the system per unit area. The minimum of this cost can be obtained by:

$$
f=\min \sum_{i=1}^{n}(a+b)
$$

where, $a$ is the amount of construction cost per unit heating area distributed to each year; $b$ is the annual operating cost per unit heating area.

\subsection{Optimization of economic model of geothermal energy consumption}

In the construction project of geothermal heating system, the cost mainly includes the construction cost in the initial phase and the operating cost in the later phase. The former refers to the cost incurred in the construction of geothermal wells, peak-shaving boiler, exchange station and pipe network, while the latter covers various costs arising in the operating phase (i.e. water and electricity, equipment depreciation and repair, material procurement and salary). These two types of cost and their correlations must be considered during the economic evaluation of geothermal energy consumption.

The peak-saving boiler was taken as an example to illustrate the optimization of the construction cost. To optimize the construction cost, it is necessary to consider the relationship between the cost and specifications of the boiler. The market survey shows that boilers with different unit loads varies greatly in cost. Hence, the cost of the boiler was computed under different demands for variable load. As shown in Figure 7 , the unit price of the boiler per unit rated power declined with the growth in rated power, and eventually converged at 210 yuan $/ \mathrm{kW}$. Therefore, if the variable load is greater than the preset value, the cost of the boiler should be 210 yuan $/ \mathrm{kW}$; if the variable load is smaller than that value, the cost of the boiler should be computed according to its rated power. The boiler construction also incurs direct cost and indirect cost of the construction project and other cost. Thus, the boiler cost was multiplied with 3.5 to cover all these costs.

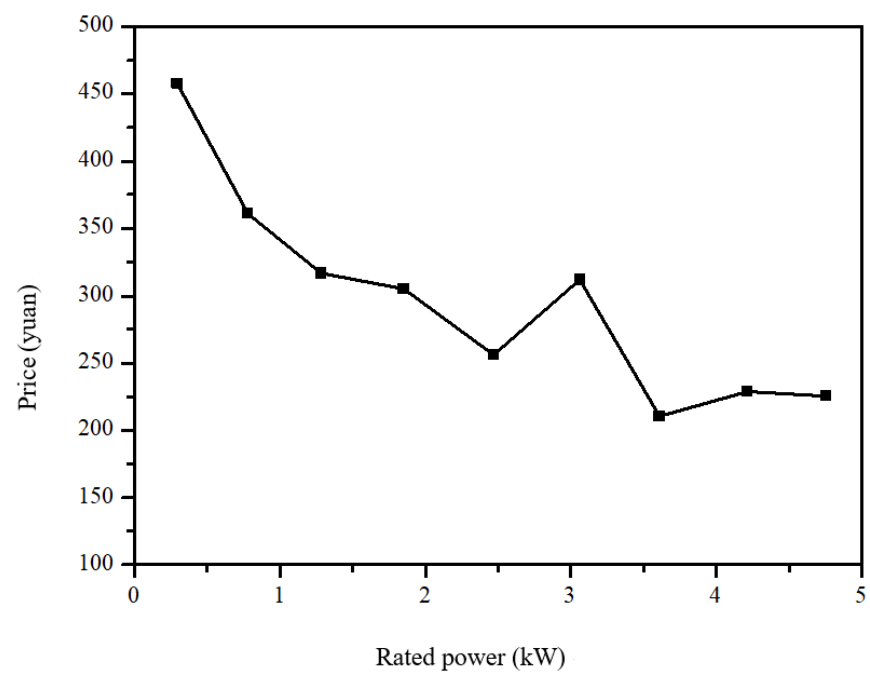

Figure 7. The unit price of the boiler per unit rated power

Considering the above construction cost and the operating cost, the total construction cost was distributed to each year by the annual worth method, and superimposed with the annual operating cost. Eventually, the optimized economic model of geothermal heating system was derived as (8).

\section{CONCLUSIONS}

In the light of the existing studies, this paper analyzes the mechanism of the technical innovation and structural upgrading of the energy industry. Considering the influencing factors of sustainable development of energy, an economic model was constructed for geothermal energy consumption via optimization analysis, and improved through mathematical analysis. The main conclusions are as follows:

(1) To improve energy mining and utilization, the management should be innovated to sort out the relations between technology, talent, knowledge and system, the innovation should focus on the development of independent intellectual property rights, and efforts should be paid to develop clean energies like solar energy, wind energy, tidal energy and geothermal energy, such as to reduce the reliance of social progress on nonrenewable energies (e.g. oil and coal).

(2) The HDD data were collected from a region, and fitted by the LS method, outputting the fourth-order polynomial equation about the HDD and temperature: $y=0.0007 x^{4}$ $0.189 x^{3}+0.0102 x^{2}+10.1206 x+71.628$.

(3) Based on industrial innovation and structural upgrading, 
a mathematical model was constructed for geothermal energy mining, development and consumption. The total construction cost was distributed to each year by the annual worth method, and superimposed with the annual operating cost. On this basis, the optimized economic model of geothermal heating system was established to enhance the economic advantages of geothermal energy.

\section{REFERENCES}

[1] Gemelli, A., Mancini, A., Longhi, S. (2011). GIS-based energy-economic model of low temperature geothermal resources: A case study in the Italian Marche region. Renewable Energy, 36(9): 2474-2483. https://doi.org/10.1016/j.renene.2011.02.014

[2] Johnson, C., Augustine, C., Goldberg, M. (2012). Jobs and economic development impact (JEDI) model geothermal user reference guide. Office of Scientific \& Technical Information Technical Reports, 1-34. https://doi.org/10.2172/1052891

[3] Liu, H.T. (2017). Evaluating the environmental and economic impacts of one China's HDR geothermal energy based heating system in a life cycle framework. International Journal of Energy Sector Management, 11(4): 609-625. https://doi.org/10.1108/ijesm-04-20160008

[4] Banerjee, S., Tiarks, J.A., Lukawski, M., Kong, S.C., Brown, R.C. (2013). Technoeconomic analysis of biofuel production and biorefinery operation utilizing geothermal energy. Energy \& Fuels, 27(3): 1381-1390. https://doi.org/10.1021/ef301898n

[5] Li, W., Wei, H.C. (1992). The past, the present and the future utilization of geothermal energy in Xiong county, Hebei province, Peoples Republic of China. Geothermics, 21(5-6): $\quad 985-990$. https://doi.org/10.1016/03756505(92)90048-e

[6] Limpasurat, A., Falcone, G., Teodoriu, C., Barrufet, M.A., Barrufet, O.O.B. (2011). Artificial geothermal energy potential of steam-flooded heavy oil reservoirs. International Journal of Oil Gas \& Coal Technology, 4(1): 31-46. https://doi.org/10.1504/ijogct.2011.037743

[7] Villarino, J., Villarino, A., De Arteaga, I., Quinteros, R., Alañón, A. (2019). A comparative energy and economic analysis between a low enthalpy geothermal design and gas, diesel and biomass technologies for a hvac system installed in an office building. Energies, 12(5): 870-885. https://doi.org/10.3390/en12050870

[8] Balat, M. (2006). Current geothermal energy potential in Turkey and use of geothermal energy. Energy Sources, Part B: Economics, Planning, and Policy, 1(1): 55-65. https://doi.org/10.1080/009083190881436

[9] Moya, D., Paredes, J., Kaparaju, P. (2018). Method for the technical, financial, economic and environmental pre-feasibility study of geothermal power plants by RETScreen - Ecuador's case study. MethodsX, 5: 524531. https://doi.org/10.1016/j.rser.2018.04.027
[10] Zhang, K., Markides, C. N., Shen, S., Chen, X., Yang, Y. (2016). Evaluation of ejector performance for an organic rankine cycle combined power and cooling system. Applied $\quad$ Energy, 184: 404-412. https://doi.org/10.1016/j.apenergy.2016.10.017

[11] Coskun, C., Oktay, Z., Dincer, I. (2011). Modified exergoeconomic modeling of geothermal power plants. Energy, 36(11): 6358-6366. https://doi.org/10.1016/j.energy.2011.09.038

[12] Buonomano, A., Calise, F., Palombo, A., Vicidomini, M. (2015). Energy and economic analysis of geothermalsolar trigeneration systems: A case study for a hotel building in Ischia. Applied Energy, 138: 224-241. https://doi.org/10.1016/j.apenergy.2014.10.076

[13] Yilmaz, C., Kanoglu, M. (2014). Thermodynamic evaluation of geothermal energy powered hydrogen production by PEM water electrolysis. Energy, 69: 592602. https://doi.org/10.1016/j.energy.2014.03.054

[14] Loutatidou, S., Arafat, H.A. (2015). Techno-economic analysis of MED and RO desalination powered by lowenthalpy geothermal energy. Desalination, 365: 277-292. https://doi.org/10.1016/j.desal.2015.03.010

[15] Lachassagne, P., Marechal, J.C., Sanjuan, B. (2009). Hydrogeological model of a high-energy geothermal field (Bouillante area, Guadeloupe, French West Indies). Hydrogeology Journal, 17(7): 1589-1606. https://doi.org/10.1007/s10040-009-0486-3

[16] Solutions, C.E., Rush, M., Shulda, S. (2011). CNCC craig campus geothermal project: 82-well closed loop GHP well field to provide geothermal energy as a common utilitiy for a new community college campus. Office of Scientific \& Technical Information Technical Reports, 1-44. https://doi.org/10.2172/1001057

[17] Nyers, J., Kajtar, L., Tomić, S., Nyers, A. (2015). Investment-savings method for energy-economic optimization of external wall thermal insulation thickness. Energy and Buildings, 86: 268-274. https://doi.org/10.1016/j.enbuild.2014.10.023

[18] Agus, H. (2018). Modeling of geothermal energy policy and its implications on geothermal energy outcomes in Indonesia. International Journal of Energy Sector Management, $12(3)$ : 449-467. https://doi.org/10.1108/ijesm-11-2017-0011

[19] Ayub, M., Mitsos, A., Ghasemi, H. (2015). Thermoeconomic analysis of a hybrid solar-binary geothermal power? plant. Energy, 87: 326-335. https://doi.org/10.1016/j.energy.2015.04.106

[20] Keçebaş, A. (2011). Performance and thermo-economic assessments of geothermal district heating system: A case study in Afyon, Turkey. Renewable Energy, 36(1): 77-83. https://doi.org/10.1016/j.renene.2010.05.022

[21] Sarah, V.E., Johan, V.B., Ben, L., William, D. (2018). Feasibility study of a low-temperature geothermal power plant for multiple economic scenarios. Energy: 155, 1004-1012. https://doi.org/10.1016/j.energy.2018.05.028 